\title{
Correction to: Canola meal and tomato pomace as novel substrates for production of thermostable Bacillus subtilis T4b xylanase with unique properties
}

\author{
Narges Torkashvand ${ }^{1} \cdot$ Mohammad Mehdi Soltan Dalal $^{1} \cdot$ Maryam Mousivand $^{2} \cdot$ Maryam Hashemi $^{2}$ (D) \\ Published online: 17 October 2020 \\ (C) Springer-Verlag GmbH Germany, part of Springer Nature 2020
}

\section{Correction to: Biomass Conversion and Biorefinery}

https://doi.org/10.1007/s13399-020-01031-2

The original version of this article unfortunately contained a mistake. During proof corrections, Mohammad Mehdi Soltan Dalal was inadvertently removed from the list of authors. The correct list of authors is shown above.

The original article has been corrected.

Publisher's note Springer Nature remains neutral with regard to jurisdictional claims in published maps and institutional affiliations.

The online version of the original article can be found at https://doi.org/ 10.1007/s13399-020-01031-2

Maryam Hashemi

hashemim@abrii.ac.ir

1 Division of Microbiology, Department of Pathobiology, School of Public Health, Food Microbiology Research Center, Tehran University of Medical Science, Tehran, Iran

2 Microbial Biotechnology Department, Agricultural Biotechnology Research Institute of Iran (ABRII), Agricultural Research Education and Extension Organization (AREEO), Karaj, Iran 